\title{
Rationale, methods and first results of the Iranian national programme for prevention of chronic diseases from childhood: CASPIAN Study
}

M.E. Motlagh, ${ }^{1}$ R. Kelishadi, ${ }^{2}$ G. Ardalan, ${ }^{3}$ R. Gheiratmand, ${ }^{4}$ R. Majdzade ${ }^{5}$ and A. Heidarzadeh ${ }^{6}$ for the CASPIAN Study Group

$$
\begin{aligned}
& \text { مُسَوِّات وطرق ونتائج البرنامج الإيراني الوطني للوقاية من الأمراض المزمنة منذ الطفولة (الدراسة القزوينية) }
\end{aligned}
$$

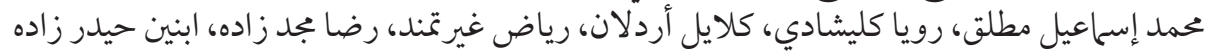

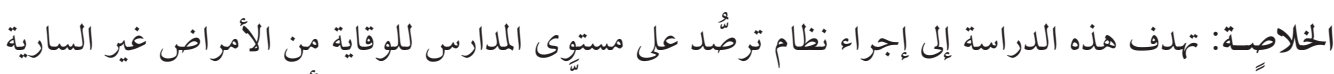

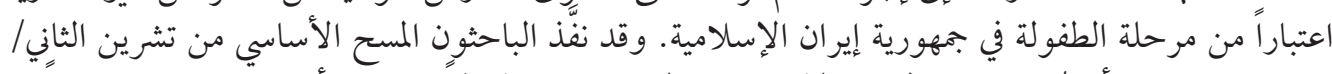

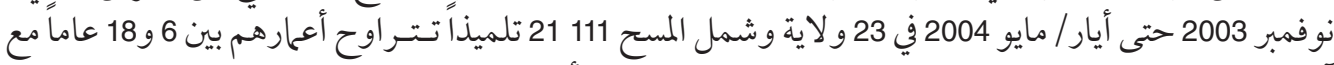

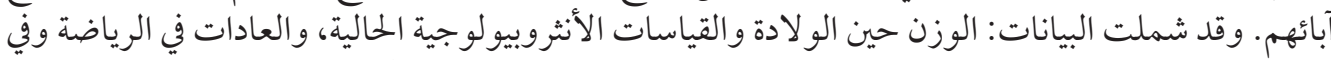

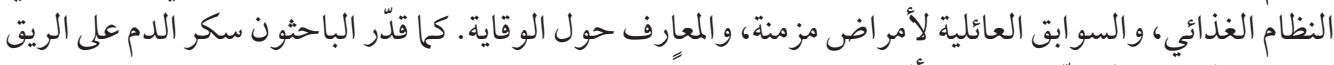

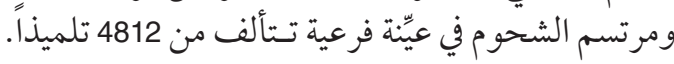

ABSTRACT The CASPIAN Study aims to implement a school-based surveillance system for prevention of noncommunicable diseases from childhood in the Islamic Republic of Iran. The baseline survey was conducted from November 2003 to May 2004 in 23 provinces among 21111 school students aged 6-18 years and their parents. The data collected included: birth weight and current anthropometric measurements; dietary and exercise habits; family history of chronic diseases; and knowledge about prevention. Fasting blood sugar and lipid profile were assessed in a subsample of 4811 students.

Principe, méthodes et premiers résultats du programme national iranien de prévention des maladies chroniques dès l'enfance : l'étude CASPIAN

RÉSUMÉ L'étude CASPIAN vise à mettre en place un système de surveillance en milieu scolaire en vue de la prévention des maladies non transmissibles dès l'enfance en République islamique d'Iran. L'étude de référence a été menée de novembre 2003 à mai 2004 dans 23 provinces auprès de 21111 élèves âgés de 6 à 18 ans et leurs parents. Les données suivantes ont été recueillies : poids de naissance et mesures anthropométriques au moment de l'étude; habitudes alimentaires et pratiques en matière d'activité physique ; antécédents familiaux de maladies chroniques ; et connaissances sur la prévention. On a établi la glycémie et le profil lipidique à jeun d'un sous-échantillon de 4811 élèves.

\footnotetext{
${ }^{1}$ Bureau of Family Health; ${ }^{3}$ Youth and School Health Office, Ministry of Health and Medical Education, Tehran, Islamic Republic of Iran.

${ }^{2}$ Department of Preventive Paediatric Cardiology, Isfahan Cardiovascular Research Centre, Isfahan University of Medical Sciences, Isfahan, Islamic Republic of Iran (Correspondence to R. Kelishadi: Kelishadi@med.mui.ac.ir).

${ }^{4}$ Bureau of Health, Ministry of Education, Tehran, Islamic Republic of Iran.

${ }^{5}$ School of Public Health and Institute of Public Health Research, Tehran University of Medical Sciences, Tehran, Islamic Republic of Iran.

${ }^{6}$ Department of Community Health, School of Medicine, Guilan University of Medical Sciences, Guilan, Islamic Republic of Iran.

Received: 22/03/06; accepted: 11/10/06
} 


\section{Introduction}

The prevalence of noncommunicable diseases (NCDs) is rising rapidly and they are no longer restricted to highly industrialized countries. In 1997 the World Health Organization (WHO) announced that NCD constituted a more significant contribution to ill health throughout the world than did infectious diseases. According to WHO estimates, by the year 2020, NCD will account for approximately three-quarters of all deaths in the developing world [1].

In developing countries, the rapid progress of modernization is associated with a cluster of NCD and unhealthy lifestyles, including smoking, physical inactivity and rapid increase in "junk" food consumption. Meanwhile, interest in childhood precursors to NCDs is increasing because there is ample evidence that the process begins early in life [2]; both behavioural and biological risk factors for NCDs persist from childhood into adulthood, and several modifiable risk factors can be tracked from childhood to adult life [3]. In the Islamic Republic of Iran the health status of children and adolescents has improved in many respects, as evidenced by lower rates of communicable diseases and declines in the nutrient deficiency diseases of the past. However rapid lifestyle changes are making them prone to chronic diseases later in life [4,5]. The attainment of optimal health through improved diet and increases in physical activity as well as tobacco control will promote decreases in chronic diseases.

It is important for policy-makers to have accurate information about NCD-related risk behaviours and risk factors in children and adolescents. For the first time in the Islamic Republic of Iran, and to our knowledge in the Eastern Mediterranean Region (EMR), a project has been initiated to provide a culturally-appropriate model for action-oriented interventions, and to implement a national school-based surveillance system for risk behaviours and risk factors for chronic diseases. The Childhood and Adolescence Surveillance and Prevention of Adult Non-Communicable Disease (CASPIAN) Study is a joint collaboration of the WHO Regional Office for the Eastern Mediterranean (WHO/EMRO) and the Iranian Ministry of Health and Medical Education and the Ministry of Education. The objective of the baseline survey was to obtain information about levels of NCDrelated risk behaviours and risk factors of children living in different provinces in order to design and implement necessary interventions in the next phases of the study.

\section{Methods}

This multicentre study in the Islamic Republic of Iran was performed from November 2003 to May 2004 in 23 provinces (out of 28) where the local authorities declared their willingness to participate.

\section{Sample}

The sample was selected to be a representative sample of around 16000000 Iranian school students from the 67000000 total population of the country, which has the following distribution of ethnic groups: Persian 51\%, Azeri 24\%, Gilaki and Mazandarani $8 \%$, Kurd $7 \%$, Arab 3\%, Lur 2\%, Baloch 2\%, Turkmen 2\% and others $1 \%$. Based on the WHO/MONICA protocol [6], the sample size was calculated as 900 students in each district of the 23 participating provinces, taking 150 students of each sex and in each of the 3 age groups under study. Hence, the total sample size in the 23 districts under study was calculated to be 20700 , which was increased to 22000 to allow for a $5 \%$ estimated missing data. The 
students were selected by multistage, random cluster sampling from different school levels of urban and rural areas of each district. Schools were stratified according to location (urban/rural) and the socioeconomic character of the catchment area, taking into consideration the proportion of the different types of schools (public/private) to avoid socioeconomic bias.

Dietary and exercise habits were assessed and anthropometric measures made for 21111 school students (96\% participation rate) aged 6-18 years living in urban and rural areas. Questionnaires were also completed about birth weight, childhood feeding, family history of chronic diseases and knowledge about prevention. In the 20 provinces which agreed to include a smoking questionnaire, we assessed smoking habits (active/passive) with an anonymous questionnaire among 11966 intermediate- and high-school students (data not reported).

Fasting blood sugar and lipid profile were measured in a subsample of 4811 students aged 6-18 years from 6 provinces located in diverse parts of the country, and with a population of different ethnicities. The local authorities in each province agreed to blood sampling; the sampling frame was $\mathrm{t}$ as described for the whole sample.

\section{Instruments and measurements}

\section{Questionnaire}

We prepared the questionnaires in Farsi based on the WHO STEPwise approach to NCD (Tools, version 9.5) and the WHO Global School Health Survey [7,8]. Under the supervision of expert health care professionals, the students and one of their parents who was invited to the school, filled out the self-administered questionnaire at the same time. The validity of the content was affirmed based on observations by a panel of experts. Item analysis and reliability measures were assessed based on a pilot study.
In addition to sociodemographic variables, the questionnaire included questions about the family history of NCD (premature CVD, osteoporosis, obesity and cancer), as well as questions about the behaviour, attitude, skills and knowledge of students and parents about a healthy lifestyle and the importance of primary prevention of NCD from early life. The parents completed the questions concerning the sociodemographic characteristics, the child's birth weight, and his/her feeding during infancy as well as the family history of chronic diseases and family dietary habits. The students completed questions about practice, knowledge and attitudes of lifestyle and prevention of NCD.

The students' self-reported physical activity pattern was assessed using Aadahl and Jorgensen's method [9]. We had previously modified and validated their questionnaire in Iranian youth [10]. This instrument is designed to measure 24 hours of sports, work and leisure time on an average weekday by rating the time spent on activity of a particular level in 9 different metabolic equivalent (MET) levels ranging from sleep/rest $(0.9$ MET) to high-intensity physical activities (>6 MET).

The knowledge scores were categorized according to the percentage of correct answers to the questions about healthy lifestyle and prevention of NCDs: low $(<30 \%)$, borderline $(30 \%-69 \%)$, and acceptable $(>70 \%)$. The scoring was based on the views of a panel of experts.

In addition to the questions about family dietary habits (e.g. type of fat used for preparing foods and type of flour used for bread), all students filled in a food frequency questionnaire that had been previously validated among Iranian youth [4]. Food items were grouped into the following categories: carbohydrates (rice, bread, pasta, potatoes), vegetables (excluding potatoes/ french fries), fruits (fresh, dried, juice), 
dairy products (milk, cheese, yogurt), proteins including both animal type (red meat, poultry, fish, egg) and plant type (beans, soy, nuts), fast foods (pizza, hamburgers, sausages) and snacks (salty/fat/sweet).

\section{Physical measurements}

All instruments were standardized before the examination, and the balances and sphygmomanometers were zero-calibrated. In schools, trained nurses recorded dates of birth, and measured height and weight twice to $\pm 0.2 \mathrm{~cm}$ and to $\pm 0.2 \mathrm{~kg}$, respectively, with subjects barefoot and lightly dressed, and recorded the averages. As a measure of obesity, body mass index (BMI) was computed as weight in kilograms divided by the square of height in metres. The BMI cutoffs from the Centers for Disease Control and Prevention (CDC) were used for the classification of the children and adolescents as underweight $(<5$ th percentile), normal (5th-84th percentile), at risk for overweight (85th-94th percentile) and overweight ( $>95$ th percentile) [11]. Waist circumference (WC) was measured with a nonelastic tape at a point midway between the lower border of the rib cage and the iliac crest at the end of normal expiration. Hip circumference (HiC) was measured at the widest part of the hip at the level of the greater trochanter to the nearest $0.5 \mathrm{~cm}$.

The nurses measured blood pressure (BP) using mercury sphygmomanometers according to a standard protocol. Elevated BP was defined as the mean systolic or diastolic BP above the 95th percentile for that age and sex, after adjusting for weight and height [12.].

For blood sampling, students were invited to attend the nearest health centre to the school, accompanied by a parent. The students were instructed to fast for 12 hours before the screening; compliance with fasting was determined by interview on the morning of examination. Blood samples were taken from the antecubital vein between 08:00 and 09:30 hours. After collecting blood samples, the participants were served a healthy snack.

The blood samples were centrifuged for 10 minutes at $3000 \mathrm{rpm}$ within $30 \mathrm{~min}$ utes of venepuncture. In each province, the biochemical analysis was performed in the central provincial laboratory, which met the standards of the National Reference Laboratory, a WHO collaborating centre in Tehran. Fasting blood sugar (FBS), highdensity lipoprotein cholesterol (HDL-C) and triglycerides (TG) were measured enzymatically by auto-analysers. HDL-C was determined after dextran sulphate magnesium chloride precipitation of non-HDL-C [13]. Low-density lipoprotein-cholesterol (LDL-C) was calculated in serum samples with $\mathrm{TG} \leq 400 \mathrm{mg} / \mathrm{dL}$ according to the Friedewald equation [14].

\section{Ethical issues}

The study was approved by the relevant ethics committees and national regulatory organizations. Our team obtained written informed consent from parents and oral assent from students after full explanation of the procedures involved.

\section{Quality assurance/quality control}

In addition to training the data collection team, we developed a detailed operation manual and distributed it to the team. A supervisor and a team of external evaluators nominated by the 2 collaborating ministries monitored performance, and checked and calibrated equipment according to standardized protocols. We designed and implemented repeat studies on a sub-sample of the students at specified time points, whereby our team made multiple measurements on the same participant to quantify variability and to identify its sources. 
For quality control of laboratory data, a sub-sample of sera was frozen and transported from different districts to the central laboratory at Isfahan Cardiovascular Research Centre (a WHO collaborating centre), which meets the standards of the National Reference Laboratory and is also under the quality control of the Department of Epidemiology, St Rafael University, Leuven, Belgium.

Data for all forms and questionnaires were entered twice and checked for completeness and inconsistencies. The supervisor of the data entry and analysis team quantified questionnaire data, including observations, interviewing, physical and laboratory measurements, and entered them into a computerized database (Microsoft Access XP). Data checking was conducted first at the district level by local supervisors to minimize missing and doubtful data, then at the national level by a group of statisticians. They evaluated the databank fields for outliers and rechecked a sample of entered questionnaires for each operator.

The quality of the data collected was monitored by the Data and Safety Monitoring Board of the project in order to identify and document problems in data quality.

The CIPP (context, input, process, and product) evaluation model was used to guide evaluation of the project [15].

\section{Data analysis}

After editing, the data were analysed by SPSS, version 13.0. Quantitative data are presented as means and standard deviation (SD). Prevalence data are expressed as percentages and compared using chi-squared tests. Analysis of variance (ANOVA) was performed to determine the differences between various age groups.

\section{Surveillance}

An integral part of the project was the design and implementation of a school-based surveillance system for NCD-related risk behaviours and risk factors based on a modified protocol of the WHO STEPwise approach to NCD in adults (Table 1).

\section{Results}

In this study, 10858 girls (51.4\%) and 10253 boys (48.6\%), mean age 12.2 (SD $3.3)$ years were studied. The characteristics of participants are presented in Table 2.

\section{Sociodemographic status}

Most of the students' fathers worked in the private sector $(34.9 \%)$ or were employees $(31.5 \%)$, and most of their mothers $(88.9 \%)$ were housewives.

Most of students' parents were literate. The mean number of household members was 5.6 (SD 1.7). Most of the students' families lived in their own house, and $42.4 \%$ of them possessed an automobile.

\section{Birth weight and history of feeding during infancy}

One-quarter of the students studied had a low or high birth weight (Table 2). Overall, $71.4 \%$ of students studied were breastfed during the first year of life, and the weaning food for $80.8 \%$ was made at home.

\section{Family history of chronic diseases}

Most students had a positive family history of chronic diseases (among parents, grandparents, uncles and aunts) (Table 2). Considering myocardial infarction, stroke and sudden death before the age of 55 years as premature CVD, $28.1 \%$ of students had a positive family history in 1 st and/or 2 nd degree relatives, with a prevalence of $3.5 \%$ in fathers and $1.0 \%$ in mothers.

\section{Students' dietary habits}

The type of fat most frequently used for food preparation in the students' homes was 
Table 1 Levels of the surveillance system: CASPIAN Study

\begin{tabular}{|c|c|c|c|}
\hline Module & $\begin{array}{c}\text { Step } 1 \\
\text { Questionnaire-based }\end{array}$ & $\begin{array}{c}\text { Step } 2 \\
\text { Physical measurements }\end{array}$ & $\begin{array}{c}\text { Step } 3 \\
\text { Biochemical analyses }\end{array}$ \\
\hline Data collection & Each 2 years & Each 2 years & Each $3-5$ years \\
\hline Core & $\begin{array}{l}\text { Family history, } \\
\text { socioeconomic and } \\
\text { demographic variables, } \\
\text { tobacco, physical } \\
\text { inactivity, nutrition }\end{array}$ & $\begin{array}{l}\text { Weight, height, waist, } \\
\text { and blood pressure }\end{array}$ & \\
\hline Expanded core & $\begin{array}{l}\text { Dietary patterns, } \\
\text { physical activities (in } \\
\text { detail), household } \\
\text { indicators }\end{array}$ & Hip girth & $\begin{array}{l}\text { Total- and high-density } \\
\text { lipoprotein cholesterol, } \\
\text { triglycerides, fasting blood } \\
\text { sugar }\end{array}$ \\
\hline $\begin{array}{l}\text { Optional } \\
\text { (examples) }\end{array}$ & Mental health, injury & Skin fold, pulse rate & $\begin{array}{l}\text { Oral glucose tolerance test \& } \\
\text { insulin among obese subjects, } \\
\text { lipoprotein A, apolipoprotein } \\
\text { A, apolipoprotein B, C-reactive } \\
\text { protein, urine }\end{array}$ \\
\hline
\end{tabular}

hydrogenated solid fat (73.8\%), followed by liquid oils (22.8\%), ghee and other types of fat. Most students usually consumed breads prepared with white wheat-flour, and $41.6 \%$ used whole-grain wheat. In general, 19.7\% of participants reported that they never added salt to table foods. The students' consumption of foods according to their school level is presented in Table 3, and shows a low frequency of consumption of fruits and vegetables and meat substitutes such as legumes and nuts, but a high frequency of snack food consumption consisting mostly of sweets/candies and salty/fatty snacks.

\section{Students' physical activity pattern}

The mean time spent on sedentary $(<3$ METs), moderate (3-6 METs) and vigorous (>6 METs) activities was 16.4, 4.6 and 0.8 hours/day respectively. Figure 1 presents the age and sex-specific percentiles for the time (hours/day) spent on moderate and vigorous physical activity; and shows lower levels of activity in girls than in boys. The mean daily time spent on watching television was 4.2 hours.

\section{Knowledge/attitude of students and parents}

An "acceptable" knowledge level was present in $24.1 \%$ of elementary-school students, and $17.2 \%$ of intermediate- and highschool students. Overall, $69.6 \%$ of parents had a positive attitude toward the regular extracurricular physical activity of their children. Of those without a positive attitude to physical activity, $46.2 \%$ declared that there was no access to a safe environment for physical activity out of school and $35.2 \%$ found it time-wasting for the school progress of their children.

\section{Anthropometric variables}

The mean weights and heights as well as waist and hip circumferences of students are presented in Table 4; they showed significant age and sex differences. The prevalence of underweight was $13.9 \%$ (8.1\% of boys and $5.7 \%$ of girls). Of those studied, $13.3 \%$ had a BMI $>85$ th percentile, i.e. $4.5 \%$ were overweight and $8.8 \%$ were at risk of being overweight (Table 2). According to the CDC cut-offs, the proportion of

المجلة الصحية لشرق المتوسط، منظمة الصحة العالمية، المجلد الخامس عشر، العلد Y، 9 +. 
Table 2 Characteristics of the study participants $(n=21111)$ : CASPIAN Study

\begin{tabular}{|c|c|}
\hline Variable & $\%$ of students \\
\hline \multicolumn{2}{|l|}{ School level } \\
\hline Elementary school & 36.1 \\
\hline Middle school & 30.8 \\
\hline High school & 33.1 \\
\hline \multicolumn{2}{|l|}{ Living area } \\
\hline Urban & 84.6 \\
\hline Rural & 15.4 \\
\hline \multicolumn{2}{|l|}{ School type } \\
\hline Public & 90.0 \\
\hline Private & 10.0 \\
\hline \multicolumn{2}{|l|}{ Type of house } \\
\hline Private & 75.8 \\
\hline Rental/with other relatives & 24.2 \\
\hline \multicolumn{2}{|l|}{ Birth weight (g) } \\
\hline$<2500$ & 14.7 \\
\hline $2500-4000$ & 75.2 \\
\hline$>4000$ & 10.1 \\
\hline \multicolumn{2}{|l|}{ Weight disorders } \\
\hline Underweight ${ }^{a}$ & 13.9 \\
\hline At risk for overweight ${ }^{b}$ & 8.8 \\
\hline Overweight $^{c}$ & 4.5 \\
\hline \multicolumn{2}{|l|}{ Positive family history ${ }^{d}$} \\
\hline Hypertension & 49.3 \\
\hline Diabetes & 26.7 \\
\hline Obesity & 48.5 \\
\hline Symptomatic osteoporosis & 11.8 \\
\hline Malignancy & 12.1 \\
\hline $\begin{array}{l}\text { Premature cardiovascular } \\
\text { disease }^{e}\end{array}$ & 28.1 \\
\hline
\end{tabular}

those overweight and at risk of overweight were $4.4 \%$ and $9.8 \%$ in elementary-school students, $3.1 \%$ and $12.2 \%$ in middle-school students and $2.6 \%$ and $11.1 \%$ in high-school students respectively.

The prevalence of weight disorders was significantly different in different districts, the lowest prevalence being in Zahedan
( $0.6 \%$ overweight and $3.1 \%$ at risk of overweight) and Shahrekord (2.3\% overweight and $6.2 \%$ at risk of overweight), and the highest prevalence being in Rasht (18.8\% at risk of overweight and $7.4 \%$ overweight) and Qom (18.4\% at risk of overweight and $7.3 \%$ overweight).

\section{Blood pressure}

The overall prevalence of systolic, diastolic and systolic and/or diastolic hypertension according to the Second Task Force Study 95th percentile cut-off points [12] were $4.2 \%, 5.4 \%$ and $7.7 \%$ respectively, with no significant sex difference.

\section{Sugar and lipid profile}

Fasting blood sugar and lipid profile was measured in 4811 students. Table 5 presents the mean serum levels. The mean serum level was 148.75 (SD 34.82) $\mathrm{mg} / \mathrm{dL}$ for total cholesterol, 84.94 (SD 30.11) $\mathrm{mg} / \mathrm{dL}$ for $\mathrm{LDL}-\mathrm{C}, 44.38$ (SD 12.17) $\mathrm{mg} / \mathrm{dL}$ for HDL-C, 81.60 (SD 11.88) mg/dL for TG, and $81.60(\mathrm{SD} 11.88) \mathrm{mg} / \mathrm{dL}$ for FBS.

\begin{tabular}{|c|c|c|c|}
\hline $\begin{array}{l}\text { groups consumed by } \\
(n=21 \text { 111): CASPIAI }\end{array}$ & $\begin{array}{l}\text { the stu } \\
\text { Study }\end{array}$ & 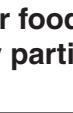 & cipants \\
\hline Food group & Times & onsun & ed/week \\
\hline & Mean & SD & Median \\
\hline Dairy products & 14.76 & 2.91 & 14.00 \\
\hline Animal protein & 7.43 & 1.01 & 7.00 \\
\hline Plant protein & 6.66 & 1.05 & 6.00 \\
\hline Fast food & 2.32 & 0.16 & 2.00 \\
\hline Salty/fatty snacks & 4.92 & 0.53 & 3.00 \\
\hline Sweets/candies & 9.79 & 1.91 & 8.00 \\
\hline$V_{\text {Vegetables }}{ }^{a}$ & 7.69 & 1.62 & 7.00 \\
\hline $\begin{array}{l}\text { Fruits (fresh, dried, } \\
\text { juice) }\end{array}$ & 8.45 & 0.58 & 8.00 \\
\hline Fruits and vegetables ${ }^{a}$ & 15.97 & 1.89 & 15.00 \\
\hline Carbohydrates & 25.27 & 1.94 & 25.00 \\
\hline
\end{tabular}

$S D=$ standard deviation.

${ }^{a}$ Potatoes and french fries not included. 

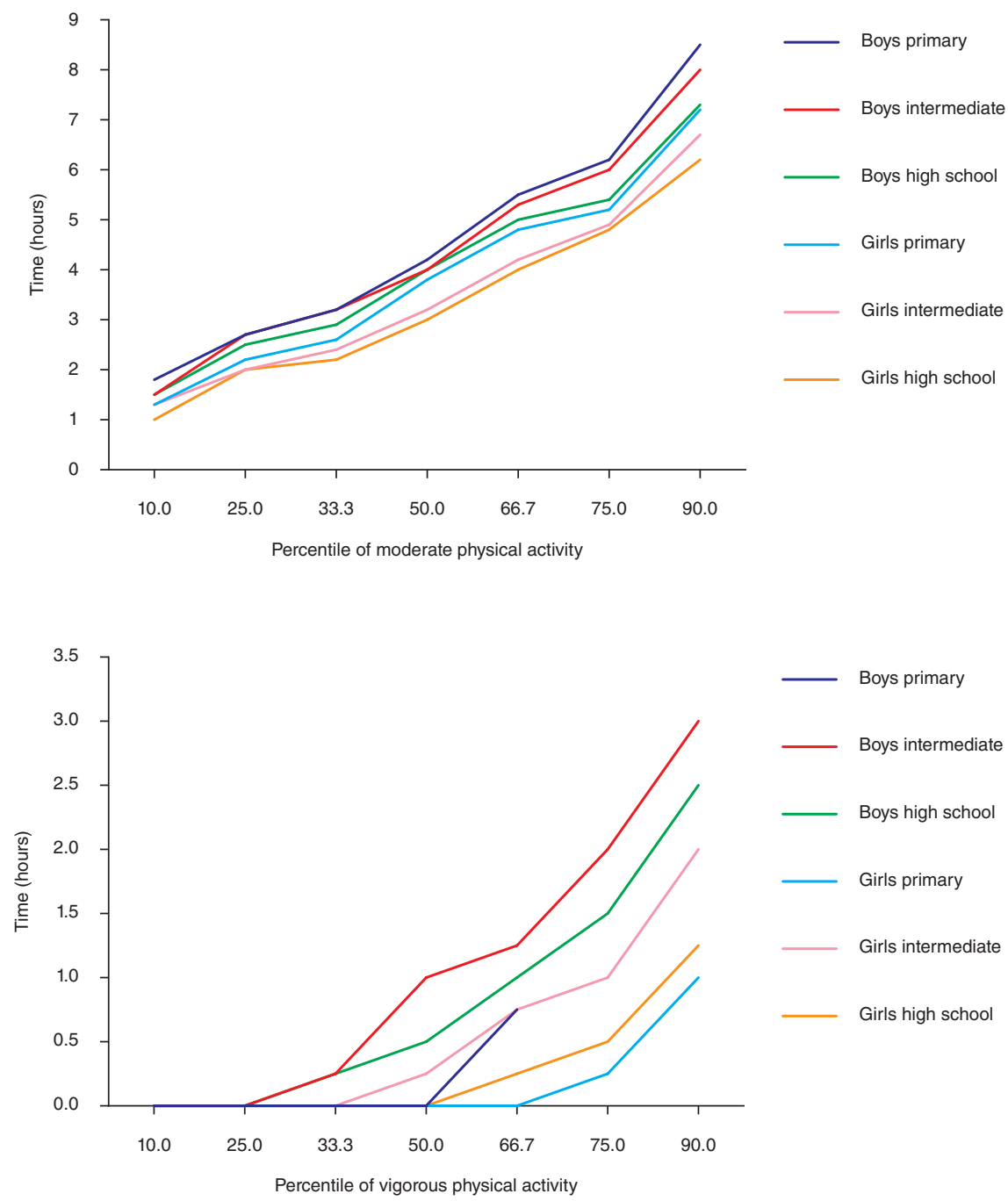

Figure 1 Percentiles of time spent on moderate and vigorous physical activity according to sex and school level ( $n=21$ 111): CASPIAN Study

\section{Discussion}

The physical activity of most of the students we studied was much lower than recommended by the American Academy of Pediatrics for their age group, and the mean time spent on sedentary activities such as TV watching was twice what is recommended
[16]. Most parents did not have a acceptable level of knowledge about lifestyle factors for NCD primary prevention, as judged by a panel of local experts.

Countries of the Middle East are believed to have the highest dietary energy surplus among developing countries, and, considering the rapid changes in the de- 
Table 4 Anthropometric measures of the study participants according to age group $(\boldsymbol{n}=21111)$

\begin{tabular}{|c|c|c|c|c|c|c|}
\hline $\begin{array}{l}\text { Sex/age } \\
\text { group (years) }\end{array}$ & $\begin{array}{l}\text { Weight (kg) } \\
\text { Mean (SD) }\end{array}$ & $\begin{array}{l}\text { Height (cm) } \\
\text { Mean (SD) }\end{array}$ & $\begin{array}{l}\text { BMI }\left(\mathbf{k g} / \mathrm{m}^{2}\right) \\
\text { Mean (SD) }\end{array}$ & $\begin{array}{l}\text { WC (cm) } \\
\text { Mean (SD) }\end{array}$ & $\begin{array}{l}\text { HiC (cm) } \\
\text { Mean (SD) }\end{array}$ & $\begin{array}{c}\text { WHR } \\
\text { Mean (SD) }\end{array}$ \\
\hline \multicolumn{7}{|l|}{ Boys } \\
\hline 6-9 & $27.1(7.1)$ & $131.6(9.3)$ & $15.9(2.8)$ & $56.9(8.3)$ & $68.8(9.8)$ & $0.8(0.006)$ \\
\hline $10-13$ & 39.7 (11.2) & $148.7(11.8)$ & 17.7 (3.5) & $64.1(10.0)$ & 78.5 (10.7) & $0.8(0.007)$ \\
\hline $14-18$ & $57.2(12.5)$ & $168.3(10.2)$ & $20.1(3.6)$ & $70.4(10.9)$ & $87.2(12.0)$ & $0.8(0.007)$ \\
\hline \multicolumn{7}{|l|}{ Girls } \\
\hline 6-9 & $26.8(7.6)$ & $129.3(9.6)$ & $15.8(2.8)$ & $55.7(7.9)$ & $69.2(9.1)$ & $0.7(0.006)$ \\
\hline $10-13$ & $41.0(10.7)$ & $149.4(10.0)$ & $18.1(3.6)$ & $63.8(10.3)$ & $80.2(11.8)$ & $0.7(0.006)$ \\
\hline $14-18$ & $52.5(9.9)$ & $159.7(8.1)$ & $20.5(3.5)$ & $68.8(8.7)$ & $89.9(10.1)$ & $0.7(0.007)$ \\
\hline
\end{tabular}

mographic profile of the EMR and the large shifts in dietary and physical activity patterns, a rapid rise in CVD risk factors is expected [17]. Most of the surveys in this part of the EMR have been performed in adult populations; however the few studies evaluating risk factors of chronic diseases among youth living in this Region have been in line with the findings of studies of other developing countries. In Bahrain, a review of data extracted from the Ministry of Health annual health report, as well as the 1981 and 1991 censuses, revealed a high prevalence of CVD risk factors among different age groups [18]. In Kuwait, where the prevalence of adult obesity is among the highest in the Arab peninsula and CVD is the leading cause of mortality, an evaluation of the risk factors for such diseases among 6- to 13-year-old schoolchildren found a high prevalence, particularly in obese subjects [19].

The Islamic Republic of Iran, among other countries of the EMR, has undergone a rapid transition in patterns of nutrition. This follows the rapid change in fertility and mortality patterns and increasing urbanization which has lead to a considerable imbalance in food consumption favouring low-nutrient diets and over-consumption among more than one-third of households [20]. Our previous studies showed an increased trend in the prevalence of CVD risk factors especially dyslipidaemia and overweight among Iranian children and adolescents [21].

In developed countries, the incidence of childhood obesity has more than doubled over the past generation [22]. In developing countries, attention is being paid to CVD, diabetes and cancer, but obesity is somewhat neglected in national and international health policies. [23]. This is partly due to the fact that this condition is not generally recognized or classified as a disease. Large, population-based studies have shown that the epidemic of childhood obesity will lead to an increase in the incidence of type 2 diabetes in the paediatric age group [24].

Worldwide, around 22 million children under 5 years of age are overweight [25]; a review from 94 developing countries showed a rising prevalence of overweight and obesity from childhood to adulthood, although rates of early childhood malnutrition also remained relatively high [26]. In the current study, we found a similar prevalence of both extremes of malnutrition, i.e. undernutrition 


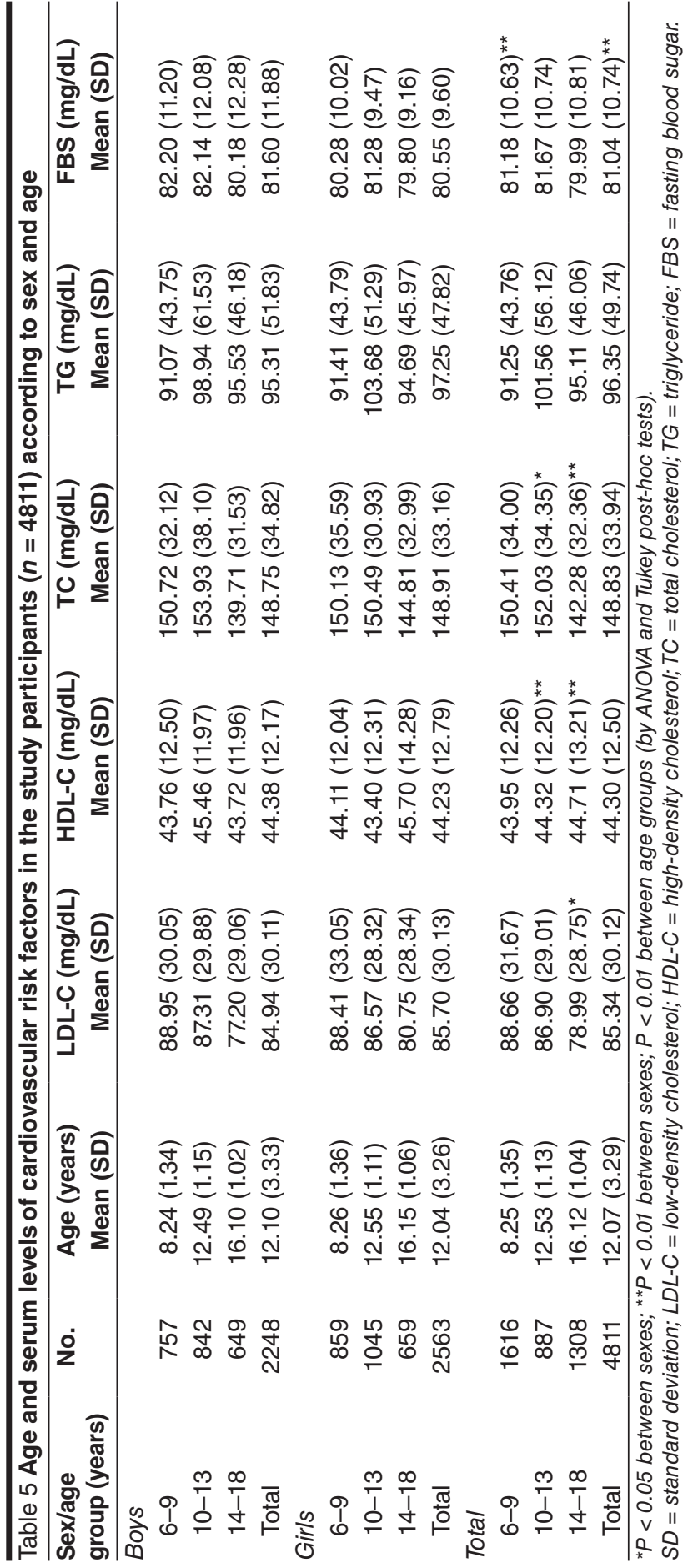

and overweight. However, large differences exist in the prevalence of overweight/obesity in children and adolescents in different provinces, but in general there was a high prevalence of overweight, especially during adolescence. This finding is consistent with previous studies performed locally in certain cities. While the prevalence of overweight was high in some large cities [4,27], in others such as Kerman it was low [28]. These findings confirm that policy-makers need the details of such variations in different parts of large countries such as the Islamic Republic of Iran, which have a great diversity in sociodemographic and lifestyle factors, as local studies cannot be generalized to the national level.

Our previous study showed that the poor state of the lipid profile in youths is not due to fat quantity, but mainly because of the improper quality of fats consumed, which are rich in saturated and trans-fatty acids [5]. In the present study too, almost $80 \%$ of families used hydrogenated solid fat, with a high consumption of deep-fried food.

Usually BMI and the percentile curves are used for clinical and epidemiological studies. However, it has been suggested that BMI may be a less sensitive indicator of fatness among children, and that it does not provide information about fatness across populations [29]. In adults, the measurement of WC has proven to be a useful tool for assessing risk for obesity-related diseases. WC correlates well 
with intra-abdominal fat mass, which has been shown to be related to an atherogenic lipoprotein profile [30]. In recent years, WC has been regarded as an important measure of adiposity in children [31]. To the best of our knowledge, for the first time in Asia, the waist and hip circumferences of children and adolescents have been assessed at national level to provide percentiles as well as cutoff values. It is documented that abdominal obesity and the metabolic syndrome constitute a major challenge for public health, and considering that lifestyle changes could have a profound influence on the development and prevention of this syndrome, intensive interventions for adopting a healthy lifestyle from childhood are warranted [32].

Considerable evidence has been mounting to suggest that reduced growth in utero and a low birth weight leads to long-term detrimental changes in adult health in terms of body structure, physiology and metabolism. Those changes have been associated with increased risk of CVD, type 2 diabetes and impaired glucose tolerance in adult life, and appear to be especially important in people who become obese [33]. This has serious implications for those people born as small babies to mothers of low body weight in times of malnutrition and who later become obese when exposed to more-Western lifestyles. Indeed, this may help explain why NCD and obesity are now becoming so prevalent in many developing countries, and why the associated health risks develop so rapidly and result in a higher degree of premature mortality in some populations or subgroups. In the present study, nearly $15 \%$ of students studied were born with a low birth weight, a finding that emphasizes the need to encourage healthy lifestyles, particularly healthy nutrition, for adolescent girls as future mothers.

Failure to achieve optimal bone mass during childhood is an underlying cause of osteoporosis later in life. Children and adolescents need to be physically active every day to achieve healthy weights and promote psychological well-being and optimal bone health, as well as to prevent CVD and other chronic diseases [34]. Our findings showed a high frequency of positive family history for osteoporosis, sedentary lifestyle and improper dietary habits that together make the children and adolescents of our community prone to osteoporosis later in life.

Public health professionals now have a responsibility to develop practical methods for prevention of chronic disease early in life by helping youth to develop healthy lifestyles from the outset [35]. NCD prevention from childhood requires a partnership between governments, national and international organizations, consumers, industry and the media. In developing countries, national planning should consider the problems of both inadequacy and excess.

We should acknowledge that certain factors might have influenced the findings of the present study, such as the presumption of some missing data and recall bias for the process of recalling and recording food intake and physical activity. Considering the large number of subjects studied, only a simple food frequency questionnaire was used in the present survey, and such data cannot provide the precise nutrient and energy intake of the subjects studied.

\section{Conclusion}

The current lifestyle of children and adolescents of our community make them prone to chronic diseases later in life. Close monitoring of children and adolescents for NCD-related risk factors and risk behaviours should be considered a public health priority in developing countries so that preventive measures can be taken in a timely manner. 


\section{Acknowledgements}

WHO/EMR grant No. TSA03/11 and the Iranian Ministry of Health Medical Education and the Ministry of Education funded the project. The authors would like to forward their sincere thanks to all the large team working on this project.

\section{References}

1. Global strategy for non-communicable disease prevention and control (draft). Geneva, World Health Organization, 1997 (WHO/NCD/GS/97.1).

2. McGill HC Jr et al. Association of coronary heart disease risk factors with microscopic qualities of coronary atherosclerosis in youth. Circulation, 2000, 102(4):374-9.

3. Williams S. Overweight at age 21: the association with body mass index in childhood and adolescence and parents' body mass index. A cohort study of New Zealanders born in 1972-1973. International journal of obesity and related metabolic disorders, 2001, 25(2):158-63.

4. Kelishadi R et al. Obesity and associated modifiable risk factors in Iranian adolescents: IHHP-HHPC. International pediatrics, 2003, 45(4):435-42.

5. Kelishadi $\mathrm{R}$ et al. Fat intake and serum lipid profile in Iranian adolescents: IHHP-HHPC. Preventive medicine, 2004, 39(4):760-6.

6. Evans $A$ et al. Trends in coronary risk factors in the WHO MONICA project. International journal of epidemiology, 2001, 30(Suppl. 1):S35-40.

7. STEPwise approach to surveillance (STEPS). Geneva, World Health Organization [website] (http://www.who.int/chp/ steps/en/, accessed 20 July 2008).

8. Global school-based student health survey (GSHS). World Health Organization [website] (http://www.who.int/chp/gshs/ en/, accessed 20 July 2008).

9. Aadahl $\mathrm{M}$, Jorgensen $\mathrm{T}$. Validation of a new self-report instrument for measuring physical activity. Medicine and science in sports and exercise, 2003, 35(7):1196202.

10. Kelishadi R et al. [Assessment of physical activity in adolescents of Isfahan]. Journal of Shahrekord University of Medical Sciences, 2001, 3(7):55-65 [in Farsi]

11. Kuczmarski RJ et al. CDC growth charts: United States. Advance data, 2000, 314(5):1-27.

12. Update on the 1987 Task Force Report on High Blood Pressure in Children and Adolescents: a working group report from the National High Blood Pressure Education Program. Working Group on Hypertension Control in Children and Adolescents. Pediatrics, 1996, 98(4 Pt1):649-58.

13. Warnick GR, Benderson J, Albers JJ. Dextran sulphate-Mg2+ precipitation procedure for quantitation of high-density lipoprotein cholesterol. Clinical chemistry, 1982, 28(6):1379-82.

14. Friedewald WT et al. Estimation of the concentration of low-density lipoprotein cholesterol in plasma, without use of the preparative ultracentrifuge. Clinical chemistry, 1972, 18(6):499-502.

15. Stufflebeam DL. The CIPP model for program evaluation. In: Madaus GF et al., eds. Evaluation models. Boston, KluwerNijhoff, 1983:117-41.

16. Gentile DA et al. Well-child visits in the video age: pediatricians and the American Academy of Pediatrics' guidelines for children's media use. Pediatrics, 2004 114(5):123541. 
17. Galal O. Nutrition-related health patterns in the Middle East. Asia Pacific journal of clinical nutrition, 2003, 12(3):337-43.

18. Hamadeh RR. Noncommunicable diseases among the Bahraini population: a review. Eastern Mediterranean health journal, 2000, 6(5-6):1091-7.

19. Moussa MA et al. Factors associated with obesity in Kuwaiti children. European journal of epidemiology, 1999, 15(1):41-9.

20. Ghassemi H, Harrison G, Mohammad K. An accelerated nutrition transition in Iran. Public health nutrition, 2002, 5(1A):14955.

21. Kelishadi R et al. Trend of atherosclerosis risk factors in children of Isfahan. Asian cardiovascular and thoracic annals, 2001, 9(1):36-40.

22. Ebbeling CB, Pawlak DB, Ludwig DS. Childhood obesity: public-health crisis, common sense cure. Lancet, 2002, 360(9331):473-82.

23. Boutayeb A, Boutayeb S. The burden of non communicable diseases in developing countries. International journal for equity in health, 2005, 4(1):2-10.

24. Obesity: preventing and managing the global epidemic. Report of a WHO Consultation on Obesity. Geneva, 3-5 June 1997, 1st ed. Geneva, World Health Organization, 1998 (WHO/NUT/NCD/98.1).

25. Moreno LA et al. Waist circumference for the screening of the metabolic syndrome in children. Acta paediatrica, 2002, 91(12):1307-12.

26. De Onis M, Blossner M. Prevalence and trends of overweight among preschool children in developing countries. American journal of clinical nutrition, 2000, 72(4):1032-9.

27. Azizi $\mathrm{F}$ et al. Dietary factors and body mass index in a group of Iranian adoles- cents: Tehran lipid and glucose study-2. International journal for vitamin and nutrition research, 2001, 71(2):123-7.

28. Janghorbani M, Parvin F. Prevalence of overweight and thinness in high-school girls in Kerman, Iran. International journal of obesity and related metabolic disorders, 1998, 22(7):629-33.

29. Reilly JJ et al. Identification of the obese child: adequacy of the body mass index for clinical practice and epidemiology. International journal of obesity and related metabolic disorders, 2000, 24:1623-7.

30. Lean MEJ et al. Waist circumference as a measure for indicating need for weight management. British medical journal, 1995, 311:158-61.

31. Freedman DS et al. Relation of circumference and skin fold thickness to lipid and insulin concentrations in children and adolescents: the Bogalusa Heart Study. American journal of clinical nutrition, 1999, 69(2):308-17.

32. Isomaa B. A major health hazard: the metabolic syndrome. Life sciences, 2003, 73(19):2395-411.

33. Cohen MS. Fetal and childhood onset of adult cardiovascular diseases. Pediatric clinics of North America, 2004, 51(6):1697-719.

34. Ulrich $\mathrm{CM}$ et al. Bone mineral density in mother-daughter pairs: Relations to lifetime exercise, lifetime milk consumption and calcium supplements. American journal of clinical nutrition, 1996, 63(1):72-9.

35. Kavey RE et al. American Heart Association guidelines for primary prevention of atherosclerotic cardiovascular disease beginning in childhood. Journal of pediatrics, 2003, 142(4):368-72. 